\title{
Produção de propágulos micorrízicos em sorgo e/ou em braquiária
}

Production of mycorrhizal propagules in sorghum and/or brachiaria

\author{
L. J. O. Lopes ${ }^{1}$, G. M. Santos ${ }^{1}$, J. S. Santos ${ }^{1}$, J. F. S. Santos ${ }^{1}$, J. J. Mendonça1 ${ }^{1}$ J. \\ L. Fagundes ${ }^{2}$, R. H. Marino ${ }^{\text {* }}$ \\ ${ }^{I}$ Departamento de Engenharia Agronômica, Universidade Federal de Sergipe, 49100-000, São Cristóvão - Sergipe, \\ Brasil \\ ${ }^{2}$ Departamento de Zootecnia, Universidade Federal de Sergipe, 49100-000, São Cristóvão - Sergipe, Brasil
}

*rehmarino@hotmail.com

(Recebido em 30 de maio de 2018; aceito em 08 de agosto de 2018)

\begin{abstract}
Os fungos micorrízicos arbusculares (FMA) são micro-organismos endofíticos capazes de promover o crescimento de plantas de interesse econômico a depender da interação microbiana com a planta, mas poucos são os trabalhos relacionados com a produção de inoculantes. O objetivo deste trabalho foi avaliar a produção de propágulos micorrízicos em cultivo sucessivo e/ou rotacionado em sorgo e em braquiária, sem o uso de estimuladores químicos. O delineamento experimental utilizado foi inteiramente ao acaso em parcelas subdivididas, cujas parcelas foram os tratamentos (três isolados de FMAs: UFLA351 - Rhizoglomus clarum, UFLA372 - Claroideoglomus etunicatum e UFLA401 - Acaulospora morrowiae) e as subparcelas os cultivos sucessivos em sorgo/braquiária e rotacional em braquiária, com quatro repetições. $\mathrm{O}$ cultivo sucessivo em sorgo ou em braquiária estimula a produção de esporos micorrízicos de $R$. clarum, C. etunicatum e A. morrowiae. A rotação de cultura sorgo-braquiária não garante incremento na esporulação, a depender do isolado micorrízico. A produção de vesículas e de arbúsculos depende da interação do fungo com a espécie de planta e não apenas da estação do ano. As vesículas podem aumentar a produção de esporos micorrízicos, a depender da interação FMA x planta e da época do ano.

Palavras-chave: Poaceae, simbiose, inóculo micorrízico
\end{abstract}

The arbuscular mycorrhizal fungi (AMF) are endophytic microorganisms able to promote the growth of plants of economic interest depending on the microbial interaction with the plant, but few are the work related to the production of inoculants. The aim of this work was to evaluate the production of mycorrhizal propagules in successive and or rotational crop in sorghum and brachiaria, without the use of chemical stimulators. The experimental design was completely randomized in subdivided plots, whose plots were the treatments (three isolates of AMF: UFLA351 - Rhizoglomus clarum, UFLA372 - Claroideoglomus etunicatum, and UFLA401 - Acaulospora morrowiae) and the subplots were the successive cultures in sorghum / brachiaria and rotational in brachiaria, with four replications. Successive cultivation in sorghum or brachiaria stimulates the production of mycorrhizal spores of $R$. clarum, C. etunicatum, and A. morrowiae. Rotation of sorghum-brachiaria culture does not guarantee an increase in sporulation, depending on the mycorrhizal isolate. The production of vesicles and arbuscules depend on the interaction of the fungus with the plant species and not only on the season of the year. The vesicles may increase the production of mycorrhizal spores, depending on the interaction AMF x plant and the time of year.

Keywords: Poaceae, symbiosis, mychorrhizal inoculum

\section{INTRODUÇÃO}

Os fungos micorrízicos arbusculares (FMAs) são micro-organismos biotróficos obrigatórios pertencentes ao Filo Glomeromycota, que realizam simbiose com cerca de $80 \%$ das espécies vegetais. Na interação simbiótica fungo x planta, os FMAs podem produzir estruturas, tais como: hifas (intra e extrarradiculares), esporos, apressórios, vesículas e arbúsculos, os quais podem ser considerados como propágulos micorrízicos [1].

Os esporos micorrízicos são responsáveis pela sobrevivência dos FMAs no ambiente, que ao germinarem emitem hifas extrarradiculares que excretam uma glicoproteína denominada de glomalina, com ação agregadora das partículas do solo capaz de favorecer a sua conservação [2]. 
As hifas extrarradiculares também aumentam a área de absorção de água e de nutrientes pelas plantas, o que pode influenciar na produção, na produtividade e na resistência a fatores adversos como a seca $[3,4,5,6]$.

Na interação fungo-planta, o apressório é uma hifa diferenciada emitida após a germinação dos esporos com a função de adesão do fungo à raiz, sendo considerado uma estrutura micorrízica essencial para ao início da colonização da planta hospedeira [7]. Durante o processo de colonização da raiz, as hifas intrarradiculares podem originar vesículas e/ou arbúsculos. As vesículas são consideradas estruturas de reserva e os arbúsculos como sítio de transferência de nutrientes da planta para o fungo e vice-versa [8], os quais podem promover o crescimento vegetativo da planta hospedeira a depender a interação microbiana $[9,10]$.

Os FMAs além de serem considerados promotores de crescimento também vêm sendo utilizados na recuperação de áreas degradadas [11, 12], na descontaminação de solos com metais pesados [13, 14] e no controle de fitopatógenos pela indução de resistência a patógenos [15]. Entretanto, apesar de ter inúmeras aplicações, poucos são os trabalhos que enfatizam a produção de propágulos micorrízicos. Neste contexto, Novais e Siqueira (2009) [16] citam que entre as espécies vegetais, as espécies de poáceas são as mais utilizadas na produção de inoculantes micorrízicos, pois estimulam a formação de propágulos fúngicos. E comercialmente, o Mycoform ${ }^{\circledR}$ estimula a produção de propágulos micorrízicos a depender da espécie fúngica $[16,17]$.

As plantas hospedeiras dos FMAs também podem ser empregadas na produção de propágulos micorrízicos, pois liberam compostos rizosféricos à base de flavonoides, que estimulam a produção de esporos, tal como observado em milho [18]. O aumento da esporulação micorrízica em poáceas pode estar também correlacionada ao fato de que estas plantas apresentam elevada colonização [19]. No entanto, não foram encontrados trabalhos relacionados com o emprego do cultivo sucessivo e/ou em rotação de isolados micorrízicos em poáceas na produção de propágulos de FMAs. Desta forma, o objetivo deste trabalho foi avaliar a produção de propágulos micorrízicos em cultivo sucessivo e/ou rotacional em sorgo e em braquiária, sem uso de estimuladores químicos.

\section{MATERIAL E MÉTODOS}

Os bioensaios foram realizados em estufa agrícola, pertencente ao Departamento de Engenharia Agronômica, no campus de São Cristóvão da Universidade Federal de Sergipe, no período de fevereiro a dezembro de 2015.

\subsection{Produção do inoculante micorrízico}

Os isolados de FMAs, UFLA351 - Rhizoglomus clarum (Nicolson \& Schenck) Sieverd, Silva \& Oehl, UFLA372 - Claroideoglomus etunicatum (Becker \& Gerdeman) Walker \& Schüßer e UFLA401 - Acaulospora morrowiae (Spain \& Schenck), foram doados pelo Laboratório de Microbiologia do Solo, pertencente à Universidade Federal de Lavras.

A multiplicação dos isolados FMAs foi realizada em solo arenoso autoclavado a $120^{\circ} \mathrm{C}$ e $1 \mathrm{~atm}$, por $1 \mathrm{~h}$ e repetido após $24 \mathrm{~h}$ este mesmo procedimento. Após o resfriamento, o solo foi distribuído em vasos plásticos previamente desinfestados com hipoclorito de sódio a $0,5 \%$ (v/v), por $20 \mathrm{~min}$, na proporção 2:1 (solo arenoso autoclavado: inoculante micorrízico). O inoculante foi adicionado entre duas camadas de solo arenoso autoclavado. Em seguida, realizou-se a semeadura com sementes de Sorghum bicolor L. Moench previamente desinfestadas em solução de álcool $70 \%$ (v/v), hipoclorito de sódio $0,1 \%(\mathrm{v} / \mathrm{v})$, por um minuto em cada, seguida pela tríplice lavagem em água destilada autoclavada por um minuto [20].

Os vasos contendo o inoculante e o sorgo foram distribuídos ao acaso em estufa agrícola com irrigação por microaspersão. Após 60 dias de cultivo, a parte aérea das plantas de sorgo foi cortada e suspensa a irrigação, por 25 dias, para estimular a produção de propágulos micorrízicos. O solo contendo os esporos e os fragmentos radiculares da planta multiplicadora colonizados por FMAs foram utilizados como inoculante micorrízico. 


\subsection{Cultivo sucessivo e/ou rotacional em sorgo/braquiária para produção de propágulos micorrízicos}

Os bioensaios foram realizados em vasos plásticos com capacidade de $0,86 \mathrm{~L}$, sendo depositada uma camada de inoculante micorrízico entre duas camadas do solo arenoso autoclavado e semeadas as sementes de sorgo (Sorghum bicolor) e/ou braquiária (B. decumbens), desinfestadas superficialmente [20]. O número de esporos presentes no inoculante micorrízico foi de 171 esporos por $100 \mathrm{~g}$ de inoculante e foi determinado segundo o método de peneiramento úmido [21]. Os vasos plásticos contendo o solo arenoso, o inoculante micorrízico e as sementes de sorgo e/ou braquiária foram distribuídos ao acaso, em estufa agrícola.

As variáveis analisadas foram: colonização micorrízica, estruturas micorrízicas (hifas, vesículas e arbúsculos), número de esporos micorrízicos após 60 dias de cultivo.

A colonização micorrízica (CM) e a percentagem de hifas, vesículas, arbúsculos, esporocarpos e apressórios foram avaliadas pelo método de intersecção segundo Giovannetti e Mosse (1980) [22] com modificação na metodologia de quantificação das variáveis. Para tanto, os fragmentos radiculares foram analisados com auxílio de microscópio ótico com lâminas quadriculadas ( 5 x 5 , em $\mathrm{mm}$ ). A porcentagem de colonização micorrízica $(\mathrm{CM})$ foi calculada pela equação 1: $C M(\%)=$ $(N T F C / N T F) \times 100$, onde NTFC - número total de fragmentos colonizados, na linha e na coluna e NTF - número total de fragmentos colonizados e não colonizados.

O número de esporos dos isolados micorrízicos foi determinado em $100 \mathrm{~g}$ de solo pelo método de peneiramento úmido [21].

\subsection{Análise estatística}

O delineamento experimental utilizado foi inteiramente ao acaso (DIC) em parcelas subdivididas. As parcelas foram três isolados micorrízicos arbusculares (UFLA351, UFLA372 e UFLA401) e as subparcelas os cultivos sucessivos em sorgo/braquiária e rotacional em braquiária entre fevereiro e dezembro/2015, com quatro repetições por tratamento. Os isolados micorrízicos foram multiplicados inicialmente em sorgo (S) durante os meses de fevereiro e abril/2015 (verão/outono), para produção do inoculante micorrízico. Em seguida, foi realizado o bioensaio 1, com o cultivo sucessivo dos isolados fúngicos em sorgo (SS: sorgo-sorgo) durante os meses de maio e julho/2015 (outono/inverno). Os inoculantes produzidos no bioensaio 1 foram multiplicados novamente em sorgo (SSS: sorgo-sorgo-sorgo) ou rotacionado em braquiária (SSB: sorgo-sorgobraquiária) no bioensaio 2 realizado entre julho e setembro/2015 (inverno/primavera). Os inoculantes produzidos em sorgo (SSSS: sorgo-sorgo-sorgo-sorgo) e em braquiária (SSBB: sorgosorgo-braquiária-braquiária) foram multiplicados em sorgo e braquiária, respectivamente, no bioensaio 3 realizado de outubro a dezembro/2015 (primavera/verão), conforme esquematizado na Figura 1.

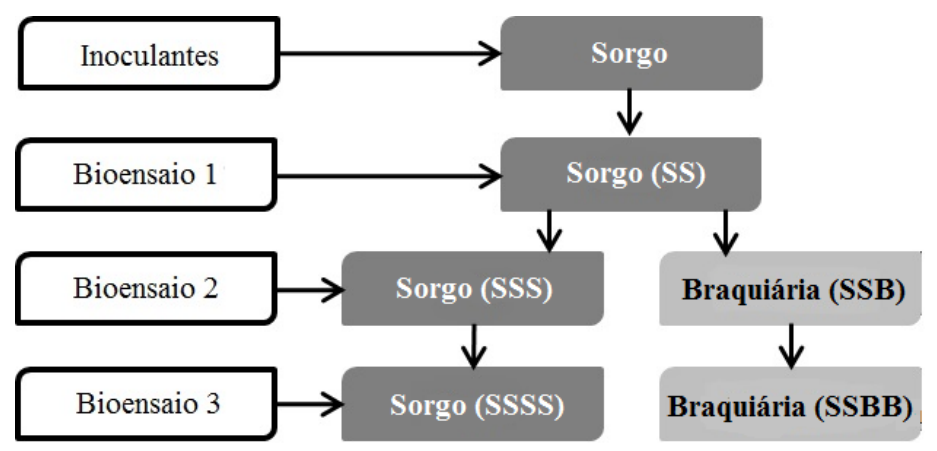

Figura 1: Relação dos bioensaios realizados visando avaliar a produção de inoculantes de fungos micorrízicos arbusculares em sorgo e em braquiária.

Os resultados obtidos foram submetidos à análise de variância (ANOVA) e nos casos em que houve diferença significativa foi aplicado o Teste de Scott-Knott a 5\% de probabilidade para 
comparação das médias. Foi realizada a correlação entre as variáveis analisadas e aplicado o Teste t a 1 e $5 \%$ de probabilidade.

\section{RESULTADOS E DISCUSSÃO}

\subsection{Produção de propágulos do isolado micorrízico UFLA351 (Rhizoglomus clarum)}

A taxa de colonização micorrízica do sorgo e da braquiária com o isolado UFLA351 variou de 29,1 a $61,1 \%$ sem influência do cultivo sucessivo deste isolados em sorgo/braquiária ou da rotação de cultura com braquiária e da estação do ano de cultivo (Tabela 1). Comparativamente, a colonização micorrízica da braquiária inoculada com Glomus (=Rhizoglomus) clarum variou de $55 \%$ a $75 \%$, mas com o emprego de Mycoform ${ }^{\circledR}$, um estimulador da interação FMA x planta [16].

Tabela 1: Colonização micorrízica (CM), vesículas (VES), arbúsculos (ARB), hifas (H) e número de esporos (ESP) do isolado UFLA351 (R. clarum) cultivado em sorgo elou braquiária por 60 dias

\begin{tabular}{cccccc}
\hline Cultivo & $\begin{array}{c}\text { CM } \\
(\%)\end{array}$ & $\begin{array}{c}\text { VES } \\
(\%)\end{array}$ & $\begin{array}{c}\text { ARB } \\
(\%)\end{array}$ & $\begin{array}{c}\mathrm{H} \\
(\%)\end{array}$ & $\begin{array}{c}\text { ESP } \\
\text { (Núm. de esporos/100 g) }\end{array}$ \\
\hline SS $^{1}$ & $61,1 \mathrm{a}^{2}$ & $16,8 \mathrm{a}$ & $4,8 \mathrm{a}$ & $32,1 \mathrm{a}$ & $61,0 \mathrm{c}$ \\
SSS & $41,0 \mathrm{a}$ & $14,3 \mathrm{a}$ & $0,0 \mathrm{~b}$ & $26,7 \mathrm{a}$ & $314,7 \mathrm{~b}$ \\
SSSS & $29,1 \mathrm{a}$ & $8,7 \mathrm{a}$ & $3,6 \mathrm{a}$ & $18,6 \mathrm{a}$ & $822,0 \mathrm{a}$ \\
SSB & $37,6 \mathrm{a}$ & $24,4 \mathrm{a}$ & $1,1 \mathrm{~b}$ & $12,1 \mathrm{a}$ & $303,3 \mathrm{~b}$ \\
SSBB & $37,4 \mathrm{a}$ & $23,3 \mathrm{a}$ & $0,0 \mathrm{~b}$ & $14,3 \mathrm{a}$ & $288,7 \mathrm{~b}$ \\
\hline
\end{tabular}

${ }^{1}$ Cultivo em: SS - sorgo-sorgo, SSSS - sorgo-sorgo-sorgo; SSB - sorgo-sorgo-braquiária, SSSS sorgo-sorgo-sorgo-sorgo e SSBB - sorgo-sorgo-braquiária-braquiária; e ${ }^{2}$ Médias seguidas de mesma letra, entre os cultivos e por variáveis, não diferem estatisticamente pelo Teste Scott-Knott a $5 \%$ de probabilidade

O cultivo sucessivo em sorgo/braquiária ou rotacional em braquiária do isolado UFLA351 também não influenciou na formação de hifas extrarradiculares e de vesículas, tal como observado em milho consorciado com sorgo [19]. Por outro lado, a percentagem de arbúsculos sofreu influência do cultivo sucessivo e/ou rotacional em sorgo e braquiária (SSBB) (Tabela 1).

$\mathrm{Na}$ literatura não foram encontradas referências relacionadas com a formação das estruturas micorrízicas em sorgo e/ou em braquiária, mas Garcia e Mendoza (2008) [23] ressaltaram que a estação do ano influenciou na formação de arbúsculos na poácea de clima temperado Paspallum vaginatum. O cultivo do isolado UFLA351 entre inverno e primavera resultou na formação de arbúsculos de 1,1\% em braquiária (SSB) e de 0,0\% em sorgo (SSS). Enquanto que, no cultivo do UFLA351 entre primavera e verão houve a produção de 3,6\% de arbúsculos em SSSS e 0,0\% em SSBB (Tabela 1). Santos et al. (2013) [24] também observaram a ausência de arbúsculos na colonização micorrízica em Sorgum arundinaceu por FMAs nativos, mas não foi mencionada a estação do ano de cultivo.

Assim, observa-se que a formação de arbúsculos do isolado UFLA351 foi influenciado pela interação do fungo com o sorgo ou a braquiária, independente da estação do ano, ao contrário do que foi observado com a poácea de clima temperado por Garcia e Mendonça (2008) [23]. Além disso, os arbúsculos são estruturas efêmeras com duração de 4 a 5 dias [7], o que pode também ter influenciado neste resultado associado ao sistema de cultivo em sorgo e/ou braquiária.

Os arbúsculos são estruturas importantes na transferência de nutrientes entre os FMAs e a planta hospedeira [1]. E as vesículas podem desempenhar papel essencial na sobrevivência dos FMAs, devido a disponibilização de fonte de carbono e de energia aos fungos, quando a planta hospedeira não pode suprir suas necessidades nutricionais [25], como na ausência dos arbúsculos. Neste trabalho, a percentagem de vesículas foi maior que a de arbúsculos em todos os cultivos (Tabela 1), o que poderá contribuir na sobrevivência do isolado UFLA351.

As vesículas e as hifas extrarradiculares também podem contribuir na formação de esporos micorrízicos, principalmente quando não há simbiose fungo-planta [25]. Entretanto, a percentagem 
de vesículas do UFLA351 não foi correlacionada com o número de esporos. Este comportamento pode ter sido resultado da interação do fungo x planta, bem como efeito da época de cultivo, pois a percentagem de hifas extrarradiculares foi correlacionada com o número de esporos $(\mathrm{r}=0,98 ; 0,01$ $\leq \mathrm{p}<0,05$ ) apenas no primeiro cultivo sucessivo em sorgo (SS), realizado durante o outono/inverno.

Angelini et al. (2012) [18] citam que a formação de esporos de FMAs foi estimulada pela presença de compostos rizosféricos à base de flavonoides liberados pelas plantas de milho. Da mesma forma, o produto comercial Mycoform ${ }^{\circledR}$, à base de isoflavonoides, resultou no incremento de 48,3\% no número de esporos do Glomus (=Rhizoglomus) clarum em Brachiaria decumbens [16]. No entanto, o cultivo sucessivo do UFLA351 em sorgo (SSSS e SSSS) resultou no incremento significativo de 415,9 a $1247,5 \%$ quando comparado ao cultivo SS. Da mesma forma, a rotação de cultura de sorgo para braquiária (SSB) e o cultivo sucessivo em braquiária (SSBB) aumentou $397,2 \%$ e $373,3 \%$ o número de esporos produzidos pelo UFLA351, mas em diferença entre os cultivos em braquiária (SSB e SSBB) (Tabela 1). Assim, o cultivo sucessivo e/ou rotacional do isolado UFLA351 em sorgo/braquiária favoreceu o incremento de esporos, mas sem a necessidade de um estimulador químico, como o Mycoform ${ }^{\circledR}$ citado por Novais e Siqueira (2009) [16].

\subsection{Produção de inoculante do isolado UFLA372 (Claroideoglomus etunicatum)}

A taxa de colonização micorrízica do sorgo e da braquiária pelo isolado UFLA372 variou de 3,6 a $24,8 \%$, sem diferença significativa entre os cultivos sucessivos sorgo/braquiária e rotacional em braquiária (Tabela 2).

Tabela 2: Colonização micorrízica (CM), vesículas (VES), arbúsculos (ARB), hifas (H) e número de esporos (ESP) do isolados UFLA372 (C. etunicatum) cultivado em sorgo elou braquiária por 60 dias

\begin{tabular}{cccccc}
\hline Cultivo & $\begin{array}{c}\text { CM } \\
(\%)\end{array}$ & $\begin{array}{c}\text { VES } \\
(\%)\end{array}$ & $\begin{array}{c}\text { ARB } \\
(\%)\end{array}$ & $\begin{array}{c}\mathrm{H} \\
(\%)\end{array}$ & $\begin{array}{c}\text { ESP } \\
\text { (Núm. de esporos/100g) }\end{array}$ \\
\hline SS $^{1}$ & $24,8 \mathrm{a}^{2}$ & $15,4 \mathrm{a}$ & - & $9,5 \mathrm{a}$ & $57,0 \mathrm{~b}$ \\
SSS & $14,9 \mathrm{a}$ & $3,5 \mathrm{~b}$ & - & $11,4 \mathrm{a}$ & $226,0 \mathrm{a}$ \\
SSSS & $20,4 \mathrm{a}$ & $19,1 \mathrm{a}$ & - & $1,3 \mathrm{a}$ & $332,0 \mathrm{a}$ \\
SSB & $24,2 \mathrm{a}$ & $8,5 \mathrm{~b}$ & - & $15,7 \mathrm{a}$ & $496,7 \mathrm{a}$ \\
SSBB & $3,6 \mathrm{a}$ & $0,0 \mathrm{~b}$ & - & $3,6 \mathrm{a}$ & $396,0 \mathrm{a}$ \\
\hline
\end{tabular}

${ }^{1}$ Cultivo em: SS - sorgo-sorgo, SSSS - sorgo-sorgo-sorgo; SSB - sorgo-sorgo-braquiária, SSSS sorgo-sorgo-sorgo-sorgo e SSBB - sorgo-sorgo-braquiária-braquiária; e ${ }^{2}$ Médias seguidas de mesma letra, entre os cultivos e por variáveis, não diferem estatisticamente pelo Teste Scott-Knott a $5 \%$ de probabilidade

Os valores de colonização micorrízica em braquiária por UFLA372 foram inferiores aos 54$55 \%$ em B. decumbens e com Glomus (=R.) etunicatum [16]. Entretanto, a taxa de colonização micorrízica pode apresentar variação a depender da origem da espécie de FMAs [16, 26].

Conforme anteriormente discutido, a interação FMA x planta e as formação das estruturas micorrízicas podem ser influenciadas pela estação do ano [23]. No cultivo do UFLA372 em sorgo (SS) durante o outono/inverno apresentou uma colonização micorrízica caracterizada pela presença de vesículas e hifas extrarradiculares; o mesmo comportamento foi observado com o cultivo em sorgo SSS e braquiária SSB realizado durante o inverno e a primavera. Na primavera/verão, no sorgo (SSSS) colonizado pelo UFLA372 foram formadas vesículas e hifas extrarradiculares, enquanto que na braquiária (SSBB) foram observadas somente hifas extrarradiculares. Além do efeito da estação do ano observa-se que o cultivo sucessivo do UFLA372 em sorgo influenciou significativamente a percentagem de vesículas, bem como o cultivo em rotação sorgo-braquiária (SSB) e sucessivo em braquiária (SSBB) (Tabela 2). Assim, observa-se que a formação das estruturas micorrízica do isolado UFLA372 foi influenciada pela espécie de planta hospedeira e pelo cultivo sucessivo, independente da estação do ano, como discutido para o isolado UFLA351. 
$\mathrm{Na}$ ausência dos arbúsculos em todos os cultivos (Tabela 2), as vesículas podem ter sido estimuladas a serem produzidas, pois estas podem suprir as necessidades de fonte de carbono e de energia dos FMAs, na ausência da simbiose fungo-planta [25].

O cultivo do isolado UFLA372 em sorgo resultou no incremento significativo de 296,5\% (SSSS) e 482,5\% (SSSS) na esporulação em comparação ao SS. E o cultivo do UFLA372 em braquiária aumentou $771,4 \%$ o número de esporos no cultivo rotacional sorgo-braquiária (SSB) e de $594,7 \%$ com o cultivo sucessivo (SSBB), quando comparado ao SS (Tabela 2).

Deve-se considerar que, o aumento da esporulação do UFLA372 com o cultivo sucessivo em sorgo/braquiária e rotacional em braquiária foi superior aos $10,9 \%$ a $86,9 \%$ observado pelo cultivo de Glomus $\left(=C\right.$.) etunicatum em braquiária (B. decumbens) com o emprego de Mycoform ${ }^{\circledR}[16]$. Este aumento da esporulação do UFLA372, pode estar associado à liberação de compostos que estimulam a esporulação micorrízica, tal como discutido para o isolado UFLA351 e por Angelini et al. (2012) em milho [18]. Desta forma, o cultivo sucessivo ou rotacional sorgo/braquiária estimulou a produção de esporos do UFLA372, sem a necessidade de um estimulador químico, o que serve como uma alternativa para produtores de inoculantes micorrízicos.

\subsection{Produção de inoculante do isolado UFLA401 (Acaulospora morrowiae)}

A taxa de colonização micorrízica do sorgo e da braquiária pelo isolado UFLA401 variou de $15,5 \%$ a $39,3 \%$ sem diferença entre o cultivo sucessivo e/ou rotacional em sorgo/braquiária (Tabela 3). Estes valores foram inferiores aos $51 \%$ obtidos em B. decumbens com A. morrowiae [16]. Entretanto, estes autores também observaram variação na taxa de colonização micorrízica entre isolados da mesma espécie de Paraglomus occultum, provavelmente por serem de origens distintas.

Tabela 3: Colonização micorrízica (CM), vesículas (VES), arbúsculos (ARB), hifas (H) e número de esporos (ESP) do isolado UFLA401 (A. morrowiae) cultivado em sorgo elou braquiária por 60 dias

\begin{tabular}{cccccc}
\hline Cultivo & $\begin{array}{c}\text { CM } \\
(\%)\end{array}$ & $\begin{array}{c}\text { VES } \\
(\%)\end{array}$ & $\begin{array}{c}\text { ARB } \\
(\%)\end{array}$ & $\begin{array}{c}\mathrm{H} \\
(\%)\end{array}$ & $\begin{array}{c}\text { ESP } \\
\text { (núm. de esporos/100g) }\end{array}$ \\
\hline SS $^{1}$ & $35,9 \mathrm{a}^{2}$ & $16,3 \mathrm{a}$ & $0,0 \mathrm{~b}$ & $19,6 \mathrm{a}$ & $117,0 \mathrm{c}$ \\
SSS & $28,5 \mathrm{a}$ & $8,8 \mathrm{a}$ & $0,0 \mathrm{~b}$ & $19,7 \mathrm{a}$ & $226,0 \mathrm{~b}$ \\
SSSS & $30,6 \mathrm{a}$ & $11,2 \mathrm{a}$ & $3,6 \mathrm{a}$ & $17,6 \mathrm{a}$ & $337,3 \mathrm{~b}$ \\
SSB & $39,3 \mathrm{a}$ & $14,3 \mathrm{a}$ & $0,0 \mathrm{~b}$ & $24,9 \mathrm{a}$ & $75,3 \mathrm{c}$ \\
SSBB & $15,5 \mathrm{a}$ & $1,5 \mathrm{a}$ & $5,3 \mathrm{a}$ & $8,7 \mathrm{a}$ & $704,0 \mathrm{a}$ \\
\hline
\end{tabular}

${ }^{1}$ Cultivo em: SS - sorgo-sorgo, SSSS - sorgo-sorgo-sorgo; SSB - sorgo-sorgo-braquiária, SSSS sorgo-sorgo-sorgo-sorgo e SSBB - sorgo-sorgo-braquiária-braquiária; e ${ }^{2}$ Médias seguidas de mesma letra, entre os cultivos e por variáveis, não diferem estatisticamente pelo Teste Scott-Knott a $5 \%$ de probabilidade

A percentagem de vesículas e de hifas não apresentou diferença significativa entre os cultivos do UFLA401 sucessivo em sorgo/braquiária ou rotacional em braquiária. No entanto, o cultivo deste isolado, na primavera/verão, estimulou a formação de arbúsculos em sorgo (SSSS) e em braquiária (SSBB), quando comparado aos demais cultivos. De forma semelhante García e Mendonza (2008) [23] relataram que houve colonização máxima por arbúsculos durante a primavera em raízes de Paspalum vaginatum, em região de clima temperado. Por outro lado, não houve formação de arbúsculos nos cultivos realizados no outono/inverno em sorgo (SS) e no inverno/primavera em sorgo (SSS) ou em braquiária (SSB) (Tabela 3). Desta forma, a formação dos arbúsculos do isolado UFLA401 depende não só da estação do ano, mas também da espécie de planta hospedeira.

Em relação à esporulação, o cultivo sucessivo do isolado UFLA401 em sorgo (SSS e SSSS) resultou no incremento significativo de 93,2 a $188,3 \%$ no número de esporos, em relação ao SS (Tabela 3). O número de esporos do UFLA401 observados no cultivo em SSSS foi correlacionado positivamente com a percentagem de vesículas $(\mathrm{r}=0,96 ; 0,01 \leq \mathrm{p}<0,05)$, o que pode estar associado a uma forma de sobrevivência do FMA, quando a planta não supre as necessidades 
nutricionais e energéticas dos fungos simbiontes [25], pela baixa percentagem de arbúsculos (Tabela 3).

O cultivo sucessivo do UFLA401 em braquiária (SSBB) também resultou no incremento significativo de 501,7\% no número de esporos em relação ao cultivo SS e de $834,9 \%$ quando comparado ao cultivo rotacional sorgo para braquiária (SSB) (Tabela 3). Comparativamente, o emprego do Mycoform, um estimulador químico da esporulação, aumentou em 66,9\% o número de esporos de A. morrowiae [16], o que demonstra o potencial do cultivo sucessivo e/ou rotacional do UFLA401 em sorgo e da braquiária na esporulação, sem a necessidade do uso de estimuladores químicos, como observado com os isolados UFLA351 e UFLA372.

De forma geral, o cultivo sucessivo em sorgo e em braquiária favoreceu a produção de propágulos dos isolados micorrízicos UFLA351, UFLA372 e UFLA401, sem a necessidade de estimuladores químicos, mas deve-se considerar que os bioensaios foram realizados nas estações de verão, inverno e primavera; e por quatro cultivos sucessivos em sorgo e dois em braquiária. Assim, é importante a continuidade dos estudos, a fim de observar a interação fungo-planta ao longo do tempo, bem como o efeito do cultivo rotacional e/ou sucessivo em sorgo e em braquiária, a longo prazo, na produção de propágulos deste isolado micorrízico.

\section{CONCLUSÃO}

O cultivo sucessivo em sorgo ou em braquiária estimula a produção de esporos micorrízicos de R. clarum, C. etunicatum e A. morrowiae.

A rotação de cultura sorgo-braquiária não garante incremento na esporulação, a depender do isolado micorrízico.

A produção de vesículas e de arbúsculos depende da interação do fungo com a espécie de planta e não apenas da estação do ano.

As vesículas podem aumentar a produção de esporos micorrízicos, a depender da interação FMA x planta e da época do ano.

\section{REFERÊNCIAS BIBLIOGRÁFICAS}

1. Miranda JCC. Cerrado: Micorriza Arbuscular - ocorrência e manejo. Planaltina: Embrapa Cerrados; 2008. $169 \mathrm{p}$.

2. Silva CF, Pereira MG, Santos VL, Miguel DL, Silva EMR. Fungos micorrízicos arbusculares: composição, comprimento de micélio extrarradicular e glomalina em áreas de mata atlântica, Rio de de Janeiro. Ciência Florestal. 2016 Abr/Jun;26(2):419-433, doi:10.5902/1980509822743

3. Fialho JS, Gomes VFF, Silva Júnior JMT. Fungos micorrízicos arbusculares e atividade enzimática em solo cultivado na Chapada do Apodi-CE. Revista Caatinga. $2011 \mathrm{Jul} / \mathrm{Set}$; 24(3):10-19.

4. Franco AD, Garica JRS, Sandoval FE, Rio MAP, Requena FRG, Cabrera OAG. Características de planta, suelo y productividad entre sorgo fertilizado e inoculado com micorriza arbuscular. Revista Mexicana de Ciências Agrícolas. 2014 Abr/Mai; 5(3):379-390.

5. Vilela LAF, Saggin Júnior OJ, Paulino HB, Siqueira JO, Santos VLS, Carneiro MAC. Arbuscular mycorrhizal fungus in microbial activity and aggregation of a cerrado oxisol in crop sequence. Ciência e Agrotecnologia. $2014 \mathrm{Jan} / \mathrm{Fev} ; 38(1): 34-42$, doi: 10.1590/S1413-70542014000100004

6. Rubin JGKR, Stürmer SL. Potencial de inóculo micorrízico e importância do comprimento do micélio para agregação de solos de ambiente fluvial. Revista Brasileira de Ciência do Solo. $2015 \mathrm{Jan} / \mathrm{Fev}$; 39(1):59-68, doi: 10.1590/01000683rbcs20150466.

7. Moreira FMS, Siqueira JO. Microbiologia e bioquímica do solo. 2 ed. Lavras: Editora UFLA; 2006. 729p.

8. Jalonen R, Timonen S, Sierra J, Nygren P. Arbuscular mycorrhizal symbioses in a cut-and-carry forage production system of legume tree Gliricidia sepium and fodder grass Dichanthium aristatum. Agroforestry Systems. 2013 Apr;87(2):319-330, doi:10.1007/s10457-012-9553-1

9. Holste EK, Holl KD, Zahawi RA, Kobe R. Reduced above ground tree growth associated with higher arbuscular mycorrhizal fungal diversity in tropical forest restoration. Ecol Evol. 2016 Oct;6(20):72537262, doi: $10.1002 /$ ece 3.2487

10. Gerlach N, Schmitz J, Polatajko A, Schlüter U, Fahnenstich H, Witt S, Fernie AR, Uroic K, Scholz U, Sonnewald U, Bucher M. An integrated functional approach to dissect systemic responses in maize to 
arbuscular mycorrhizal symbiosis. Plant, Cell \& Environment. 2015 Aug;38(8):1591-1612, doi: $10.1111 /$ pce. 12508

11. Colodete CM, Dobbss BL, Ramos AC. Aplicação das micorrizas arbusculares na recuperação de áreas impactadas. Revista Natureza on line. 2014 Jan/Mar;11(1):31-37.

12. Carneiro RFV, Cardozo Júnior FM, Pereira, LF, Araújo ASF, Silva GA. Fungos micorrízicos arbusculares como indicadores da recuperação de áreas degradadas no Nordeste do Brasil. Revista Ciência Agronômica. 2012 Out/Dez;43(4):648-657.

13. Nakatani AS, Siqueira JO, Soares CRFS, Lambais MR. Comunidades microbianas, atividade enzimática e fungos micorrízicos em solo rizosférico de "Landfarming" de resíduos petroquímicos. Revista Brasileira de Ciências do Solo. 2008 Ago;32(4):1501-1512, doi: 10.1590/S0100-06832008000400014

14. Moreira H, Marques APGC, Rangel AOSS, Castro PML. Heavy metal accumulation in plant species indigenous to contaminated Portuguese site: prospects for phytoremediation. Water Air Soil Pollution. 2011 Out;221(1-4):377-389, doi: 10.1007/s11270-011-0797-6

15. Ortega EP, Noval BML, Coca BM, Noval WTL, Carmona AM, Hernández A., León, O. Induction of defense mechanisms in mycorrhized tomato plants against the attack of Oidiopsis taurica (Lev.) Salm. Cultivos Tropicales. 2015 Fev/Mar;36(1):94-102.

16. Novais CB, Siqueira JO. Aplicação de formononetina na colonização e esporulação de fungos micorrízicos em braquiária. Pesquisa Agropecuária Brasileira. 2009 Mai;44(5):496-502, doi: 10.1590/S0100-204X2009000500009

17. Cordeiro MAS, Ferreira DA, Paulio HB, Souza CRF, Siqueira JO, Carneiro MA. Mycorrhization stimulant based in formononetin associated to fungicide and doses of phosphorus in soybean in the cerrado. Bioscience Journal. 2015 Jul/Ago;31(4):1062-1070, doi: 10.14393/BJ-v31n4a2015-26185

18. Angelini GAR, Loss A, Pereira MG, Torres JLR, Saggin Júnior, OJ. Colonização micorrízica, densidade de esporos e diversidade de fungos micorrízicos arbusculares em solo de Cerrado sob plantio direto e convencional. Semina: Ciências Agrárias. 2012 Jan/Mar;33(1):115-130, doi: 10.5433/16790359.2012v33n1p115

19. Reis RJA, Campos SA, Martins GSL, Jesus EL, Bastiani MLR, Campos ANR. Efeitos de plantas de cobertura nas associações do milho (Zea Mays L.) com fungos benéficos do solo. Revista Brasileira de Agropecuária Sustentável. 2012 Dez;2(2):75-80, doi: 10.21206/rbas.v2i2.169

20. Alfenas AC, Mafia RG. Métodos em fitopatologia. 1. ed. Viçosa: UFV; 2007. 382p.

21. Gerdemann JW, Nicolson TH. Spores of mycorrhizal endogone species extracted from soil by wet-sieving and decanting. Transactions of British Mycological Society. 1963 Jun;46(2):235-244, doi: 10.1016/S0007-1536(63)80079-0

22. Giovannetti M, Mosse B. An evaluation of techniques for measuring vesicular arbuscular mycorrhizal infection in roots. New Phytologist.1980 Mar;84(3):489-500, doi: 10.1111/j.1469-137.1980.tb04556.x.

23. García IV, Mendonza RE. Relationships among soil properties, plant nutrition and arbuscular mycorrhizal fungi-plant symbioses in a temperate grassland along hydrologic, saline and sodic gradientes. FEMS Microbiology Ecology. 2008 Mar;63(3):359-371, doi: 10.1111/j.1574-6941.2008.00441.x

24. Santos EA, Ferreira LR, Costa MD, Silva MCS, Reis MR, França AC. Occurrence of symbiotic fungi and rhizospheric phosphate solubilization in weeds. Acta Scientiarum. Agronomy. 2013 Jan/Mar;35(1):4955, doi: 10.4025/actasciagron.v35i1.15047

25. Saggin Júnior OJ, Silva EMR. Micorriza Arbuscular: Papel, funcionamento e aplicação da simbiose. Brasília: Embrapa. 2005. In: Aquino AM, Assis RL. editors. Processos biológicos no sistema solo-planta: Ferramentas para uma agricultura sustentável. p.101-150.

26. Walder F, Niemann H, Natarajan M, Lehmann MF, Boller T, Wiemken A. Mycorrhizal networks: common goods of plants under unequal terms of trade. Plant Physiology. 2012 Jun;159(2):789-797, doi: 10.1104/pp.112.195727 